\title{
Study on Pyrolysis Characteristics of Coal and Combustion Gas Release in Inert Environment
}

\author{
Liang Dong $\mathbb{D}^{1},{ }^{1}$ Ziming Wang, ${ }^{1}$ Yadong Zhang, ${ }^{1}$ Junyu Lu, ${ }^{1}$ Enhui Zhou $\mathbb{D}^{1}$, \\ Chenlong Duan $\mathbb{1}^{1},{ }^{1}$ and Xiaoqiang $\mathbf{C a o}^{2}$ \\ ${ }^{1}$ School of Chemical Engineering and Technology, China University of Mining and Technology, 22116 Xuzhou, China \\ ${ }^{2}$ School of Chemistry and Environmental Engineering, Shandong University of Science and Technology, 26659 Qingdao, China \\ Correspondence should be addressed to Enhui Zhou; zeh_cumt@163.com and Chenlong Duan; 52417273@qq.com
}

Received 16 April 2019; Revised 27 July 2019; Accepted 3 October 2019; Published 6 November 2019

Academic Editor: Jolanta N. Latosinska

Copyright (c) 2019 Liang Dong et al. This is an open access article distributed under the Creative Commons Attribution License, which permits unrestricted use, distribution, and reproduction in any medium, provided the original work is properly cited.

\begin{abstract}
In this study, thermogravimetric analysis (TGA) coupled with Fourier transform infrared (FTIR) spectroscopy was used to heat the coal samples of six different coalification degrees from room temperature to $1000^{\circ} \mathrm{C}$ at $20^{\circ} \mathrm{C} \cdot \mathrm{min}^{-1}$ under nitrogen atmosphere. The influence of coal degree and pyrolysis temperature on the content of pyrolysis products of coal was analyzed by the TG/DTG curve. FTIR spectroscopy was used to obtain the IR spectra of generated gases and study their variation at different temperatures in the process of coal heating without oxygen, and the gas release during pyrolysis was discussed. The results showed that the pyrolysis reaction initiated at $400^{\circ} \mathrm{C}$ and ended at $800^{\circ} \mathrm{C}$. The maximum mass loss occurred in the temperature range of 480 to $500^{\circ} \mathrm{C}$. The values of maximum and minimum weight loss rates were 32.72 and $18.89 \%$, respectively. The mass loss during the pyrolysis process corresponded well with the volatile matter contained in the sample. Permanent gas analysis and IR spectrum analysis indicated that when the temperature was $600^{\circ} \mathrm{C}$, the peak value of methane $\left(\mathrm{CH}_{4}\right)$ appeared at 3016 wave, indicating the generation of $\mathrm{CH}_{4}$ at this time. When the temperature reached $700^{\circ} \mathrm{C}$, the peak area of 2360 wave increased, all coal samples began to release carbon dioxide $\left(\mathrm{CO}_{2}\right)$, release rate of $\mathrm{CH}_{4}$ gas decreased, and yield of $\mathrm{CO}_{2}$ was maximized. At $800^{\circ} \mathrm{C}$, all peaks of 3160 wave disappeared, indicating that there was no unreacted short-chain release at this temperature. At the same time, the pyrolysis reaction tended to remove the excess hydrogen-oxygen conjugates in the carbon structure and release them in the form of water vapor.
\end{abstract}

\section{Introduction}

Spontaneous combustion of coal is an undesirable phenomenon in coal mining and storage. Almost all the coal mining countries are disturbed by this hazardous activity [1-3]. In major coal-producing countries, such as China, the United States, India, and Indonesia, large quantities of coal resources are destroyed every year due to spontaneous combustion of coal [4]. This causes not only extensive economic losses but also a series of environmental and safety problems. Besides, the self-heating of coal $[5,6]$ affects its molecular structure, elemental composition, and other properties.

Pyrolysis characteristics of coal have always been the focus of research. From the microscopic perspective of the pyrolysis reactivity of the lithofacies microscopic components to the study of various small experimental bench pyrolysis products, the basic laws of bituminous pyrolysis have been obtained [7-9]. With increasing demands of environmentally friendly coal blending, the research on the pyrolysis characteristics of coal blending has also been put on the agenda. Although the basic research on slow heating pyrolysis faces a certain controversy related to the significance of semi-industrial tests or industrial tests, investigation of the pyrolysis of coal blended under an inert atmosphere can help reveal the precipitation rule of volatiles and the interaction between coal blends. This can help researchers obtain some basic data.

In recent years, application of thermal analysis technology to study the pyrolysis characteristics of coal [10-12] and other minerals [13-15] has been widely recognized. Many scholars have carried out a series of studies on 
spontaneous combustion of coal using equipment such as thermogravimetric (TG) analyzers and analyzed various factors and laws affecting spontaneous combustion, aiming to provide theoretical support for reducing the spontaneous combustion hazard of coal. Zhang et al. [16] used TG/differential scanning calorimetry (DSC) analysis and constructed mathematical models to compare the changes in heat flow and kinetic parameters before and after CAIT (defined as the lowest temperature of coal spontaneous combustion in the absence of external sources of ignition). The results showed that the Gaussian mixture model could be used to fit the heat flux curve of the spontaneous combustion of coal. Xiao et al. [17] used the TG method to analyze the particle size and temperature in order to study the relationship between the coal spontaneous combustion index gas and the critical temperature. The effect of rate and oxygen concentration on the critical temperature was also investigated. The results showed that the critical temperature increased with the increase in heating rate and decreased with the increase in particle size. When the heating rate was $20^{\circ} \mathrm{C} \cdot \mathrm{min}^{-1}$ and the oxygen concentration was 14.9 mass $\%$ (13 vol.\%), the critical temperature reached the maximum, and at the same time, when the temperature of the coal exceeded the critical temperature, the concentration of carbon monoxide $(\mathrm{CO})$ and carbon dioxide $\left(\mathrm{CO}_{2}\right)$ tended to increase. Based on this, the TGA and Fourier transform infrared (FTIR) spectroscopy combined experimental device has been widely used in the field of pyrolysis due to its rapid and continuous detection and has achieved good results [18-24]. Wang et al. [25] used the TG-FTIR method and in situ IR analysis to study the kinetics and mechanism of coal oxidation weight gain phenomenon. The results showed mass loss during the oxidation and pyrolysis process of coal, but in the oxidation process of coal, the medium mass gain phenomenon was particularly noticeable. Analysis of FTIR spectroscopy results indicated that more $\mathrm{CO}$ and $\mathrm{CO}_{2}$ are produced in the oxidation process than in the pyrolysis process.

Some scholars have also studied the oxygen concentration and characteristics of spontaneous combustion of coal under laboratory conditions. Zhang et al. [26] analyzed the evolution of mass, heat, and gaseous products during spontaneous combustion of coal. The results showed that the mass loss rate in the combustion stage was significantly higher than that in other stages, and with the decrease in oxygen concentration, the combustion of coal was obviously delayed. The temperature of the exothermic zone increased, and the temperature at which the corresponding $\mathrm{CO}$ and $\mathrm{CO}_{2}$ production reached the maximum was also delayed. Qi et al. [27] conducted a thermodynamic study on the reaction process of coal in a low-oxygen environment and analyzed the kinetics of the test results. The results revealed that the effects of oxygen concentration on different characteristic temperatures during coal spontaneous combustion were different. The influence of oxygen concentration on the reaction mechanism and kinetic parameters depends on the grade and reaction stage of coal. Guo et al. [28] studied the law of formation of hydrocarbon index gas of coal during spontaneous combustion in a low-oxygen environment. The results showed that the enhancement in a low-oxygen environment can reduce the increasing trend of alkane index gas volume fraction.

However, the distribution of oxygen in the coal heap is not uniform, and the area with high oxygen content first undergoes spontaneous combustion. When the combustion reaches a certain temperature, the part with low oxygen content in the coal pile gets affected, and the temperature increases, causing the coal to undergo pyrolysis reaction, producing harmful gases and endangering the environmental health and personnel safety.

This study aimed at the specific reality of the Wuhai mining area, from the perspective of coal quality. In this study, TG analysis coupled with FTIR spectroscopy was used to heat the coal samples of six different coalification degrees from room temperature to $1000^{\circ} \mathrm{C}$ at $20^{\circ} \mathrm{C} \cdot \mathrm{min}^{-1}$ under nitrogen atmosphere. The influence of coal degree and pyrolysis temperature on the content of pyrolysis products of coal was analyzed by the TG/DTG curve. The inert gas environment was used to simulate the anoxic environment in the coal pile, and a TG analyzer was used to conduct slow pyrolysis of the mixed coal in the inert atmosphere, so as to explore the gas release rule in the pyrolysis process. Furthermore, ray photoelectron spectrometer was utilized to analyze the distribution law of gas components evolved at different temperatures.

\section{Experimental}

2.1. Instruments. The TG-FTIR test system was connected with a dedicated interface using a TG 209 F3 Tarsus TG analyzer and a Tensor27 FTIR analyzer. The TG analyzer from the NETZSCH group was used to heat the sample from room temperature to $1000^{\circ} \mathrm{C}$ at a rate of $20^{\circ} \mathrm{C} \cdot \mathrm{min}^{-1}$ under nitrogen atmosphere. The microbalance was used to measure the real-time mass change of the coal, and the carrier gas was used to feed the gas generated in the coal pyrolysis into the FTIR system for further analysis. The analysis procedure is as follows: six coal samples ( $3 \mathrm{mg}$ each) were placed in a ceramic crucible of a synchronous thermal analyzer. The coal samples were pyrolyzed consecutively in the synchronous thermal analyzer under nitrogen environment. Before each experiment, the sample was further ground to a smaller size to eliminate the influence of thermal effects on the TG measurements. The experiment reached a maximum temperature of $900^{\circ} \mathrm{C}$ from $35^{\circ} \mathrm{C}$ with an increasing rate of $20^{\circ} \mathrm{C} \cdot \mathrm{min}^{-1}$. At the end of pyrolysis, the TG and DTG curves of the six coal samples were obtained. X-ray photoelectron spectroscopy was used to analyze the distribution law of gas components evolved at different temperatures. In order to ensure the accuracy of the measurement results, prior to the test, the TG analyzer was calibrated with Curie point of ferromagnetic material according to the calibration rules. Curie point is the temperature point at which ferromagnetic material changes from ferromagnetism to paramagnetism state during heating. Magnetic field needs to be loaded during calibration. When the temperature increases to the Curie point, the magnetic field changes, magnetic field attraction disappears, 
TABle 1: Proximate analysis of the investigated samples.

\begin{tabular}{|c|c|c|c|c|c|c|c|c|c|c|c|c|}
\hline \multirow{2}{*}{ Sample } & \multirow{2}{*}{ Type } & \multicolumn{5}{|c|}{ Industrial analysis } & \multirow{2}{*}{\multicolumn{2}{|c|}{$\begin{array}{c}\text { HHV LHV } \\
\text { Card (g) }\end{array}$}} & \multicolumn{4}{|c|}{ Elemental analysis } \\
\hline & & $M_{t}(\%)$ & $A_{\mathrm{d}}(\%)$ & $V_{\mathrm{d}}(\%)$ & $S_{t . \mathrm{d}}(\%)$ & $F C_{\mathrm{ad}}(\%)$ & & & $C_{\mathrm{ad}}$ & $H_{\mathrm{ad}}$ & $N_{\text {ad }}$ & $\mathrm{O}_{\mathrm{ad}}$ \\
\hline a & High-volatile C bituminous & 2.06 & 15.2 & 21.77 & 1.17 & 62.19 & 6780 & 6425 & 71.14 & 4 & 1.05 & 5.81 \\
\hline $\mathrm{b}$ & High-volatile A bituminous & 3.9 & 9.36 & 30.81 & 5.66 & 59.36 & 7804 & 7246 & 77.27 & 4.88 & 1.28 & 4.99 \\
\hline c & Sub-bituminous C & 1.6 & 30.19 & & & & 5423 & 5156 & 55.26 & 3.49 & 0.9 & 7.58 \\
\hline $\mathrm{d}$ & Bituminous & 1.83 & 8.74 & 18.29 & 1.68 & 71.64 & 7449 & 7091 & 80.88 & 4.21 & 1.23 & 2.38 \\
\hline e & Sub-bituminous B & 1.33 & 19.27 & 20.82 & 2.38 & 59.43 & 6630 & 6339 & 71 & 4.06 & 1.19 & 1.95 \\
\hline f & Sub-bituminous B & 2.6 & 11.78 & 29.03 & 4.08 & 58.99 & 7538 & 7101 & 76.41 & 4.73 & 1.36 & 3.36 \\
\hline
\end{tabular}

and the apparent mass of the material decreases, that is, the weight loss occurs. Moreover, the difference between the standard value and the measured value is the temperature correction value.

Coal samples used in this study were collected from the Wuhai mining area, China. The bulk coal sample was crushed using jaw crusher and ground in a ball mill to give fractions of mean particle size below $100 \mu \mathrm{m}$ and subsequently dried in air at $80^{\circ} \mathrm{C}$ for $4 \mathrm{~h}$. Proximate analysis of raw coal was carried out according to GB/T 212, 213, 214, and 206 Standard. Results of the test method are listed in Table 1. The moisture $\left(M_{t}\right)$ and volatile matter $\left(V_{\mathrm{d}}\right)$ of coal samples $\mathrm{b}$ and $\mathrm{f}$ are higher than those of other coal types, which are clarified as low-rank coal. The ash content $\left(A_{\mathrm{d}}\right)$ of coal sample $c$ is the highest, and the calorific value is the lowest, while coal sample $\mathrm{d}$ has the highest fixed carbon $\left(F C_{\text {ad }}\right)$ content and the lowest $A_{\mathrm{d}}$. As a result, proximate analysis shows that coal samples $b, c$, and $f$ are high-sulfur containing coals; and coal samples a, d, and e are mediumsulfur coals. Furthermore, ultimate analysis was carried out to show that the higher the carbon content, the lower the oxygen content and the higher the heat.

\section{Results and Discussion}

3.1. TG and DTG Analysis of Pyrolysis Characteristics. In order to study the pyrolysis characteristics of coal, TG and DTG analysis was carried out. The TG analysis reflects the change in mass of the sample with the increase in the temperature, and the results are shown in Figure 1. The sample begins to lose weight when heated to about $400^{\circ} \mathrm{C}$. When the temperature exceeds $800^{\circ} \mathrm{C}$, the curve becomes smooth and the weight loss is almost completed. The number on the right indicates the mass remaining at the end of the pyrolysis. The mass lost during the pyrolysis process is essentially the same as the mass of the volatiles listed in Table 1 . The results indicate that, in the anaerobic pyrolysis, mainly the volatile matter is pyrolyzed. Noteworthy, the curves of sample a and sample e are very close, which indicate that different coal types do not affect pyrolysis.

In order to analyze the instantaneous change of mass in the pyrolysis process, the TG results were calculated differentially and DTG curves were obtained. The results are shown in Figure 2. First, for all samples, the DTG peaks occur at around $480^{\circ} \mathrm{C}$, indicating that the maximum mass loss (MML) occurs at this temperature. For samples $b$ and $f$, pyrolysis occurs at $380^{\circ} \mathrm{C}$, before MML. For samples b and c, some of the material cleaves at higher temperatures. For

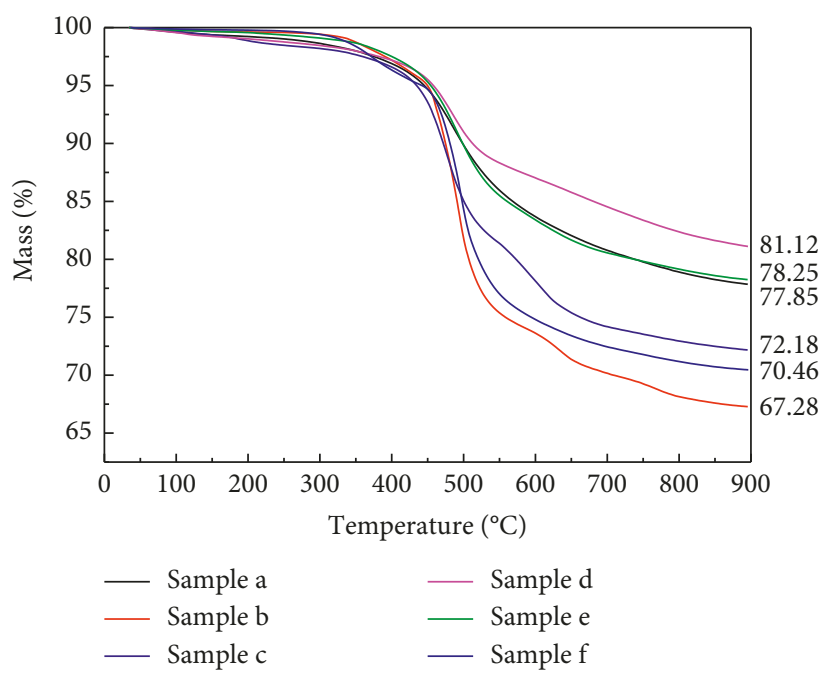

FIgURE 1: TG analysis of coal samples.

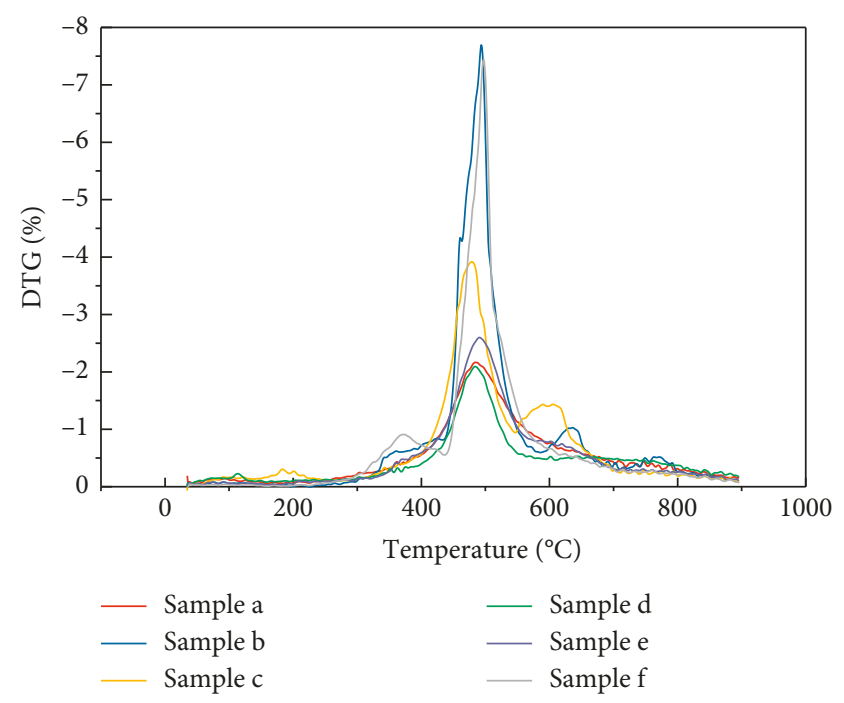

FIgURE 2: DTG analysis of coal samples.

other samples, pyrolysis mainly occurs within the MML temperature range. In order to reduce experimental error, three parallel experiments were carried out, to measure the DTG curves under the same experimental conditions. It was found that the peak temperature difference of DTG measured by three experiments was less than $4^{\circ} \mathrm{C}$.

Table 2 lists the operating conditions of the experiments. Table 2 summarizes that the pyrolysis of six types of coal can 
TABLE 2: The operating conditions of the experiments.

\begin{tabular}{lccccc}
\hline Sample & $\begin{array}{c}\text { Peak temperature } \\
\left({ }^{\circ} \mathrm{C}\right)\end{array}$ & $\begin{array}{c}\text { Mass loss } \\
(\%)\end{array}$ & $\begin{array}{c}\text { Drying and desorption stage } \\
\left({ }^{\circ} \mathrm{C}\right)\end{array}$ & $\begin{array}{c}\text { Reaction intervals } \\
\text { Decomposition reaction } \\
\left({ }^{\circ} \mathrm{C}\right)\end{array}$ & $\begin{array}{c}\text { Polycondensation reaction } \\
\left({ }^{\circ} \mathrm{C}\right)\end{array}$ \\
\hline $\mathrm{a}$ & 484 & 22.15 & $35-398$ & $399-655$ & $656-900$ \\
$\mathrm{~b}$ & 495 & 32.72 & $35-345$ & $346-570$ & $571-900$ \\
$\mathrm{c}$ & 480 & 27.82 & $35-348$ & $349-550$ & $551-900$ \\
$\mathrm{~d}$ & 482 & 18.89 & $35-340$ & $341-530$ & $531-900$ \\
$\mathrm{e}$ & 490 & 21.75 & $35-340$ & $341-576$ & $577-900$ \\
$\mathrm{f}$ & 498 & 29.54 & $35-340$ & $341-600$ & $601-900$ \\
\hline
\end{tabular}

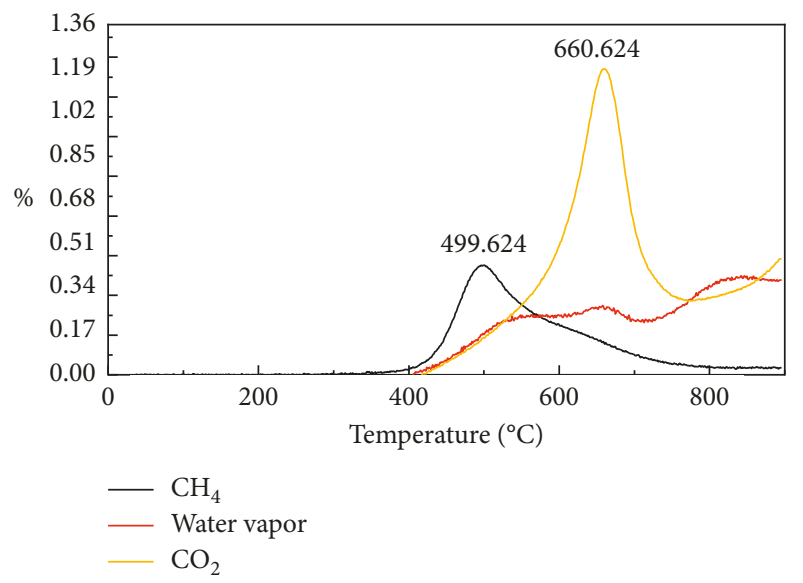

(a)
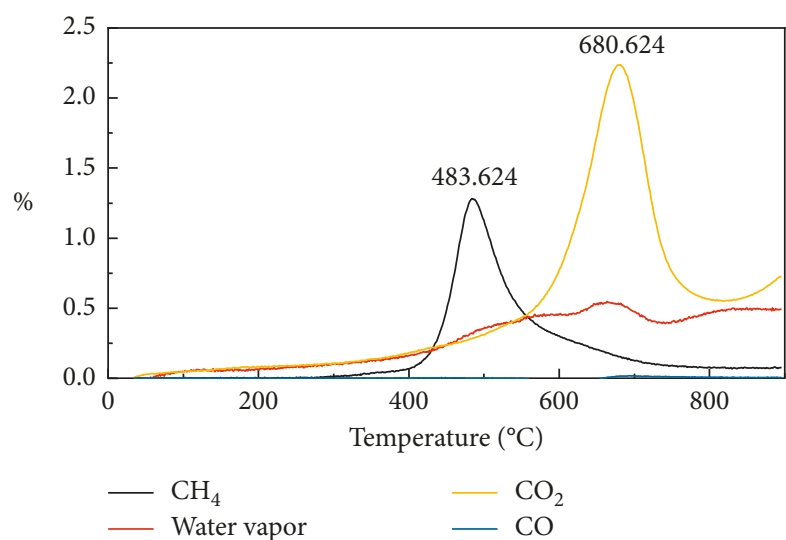

(c)

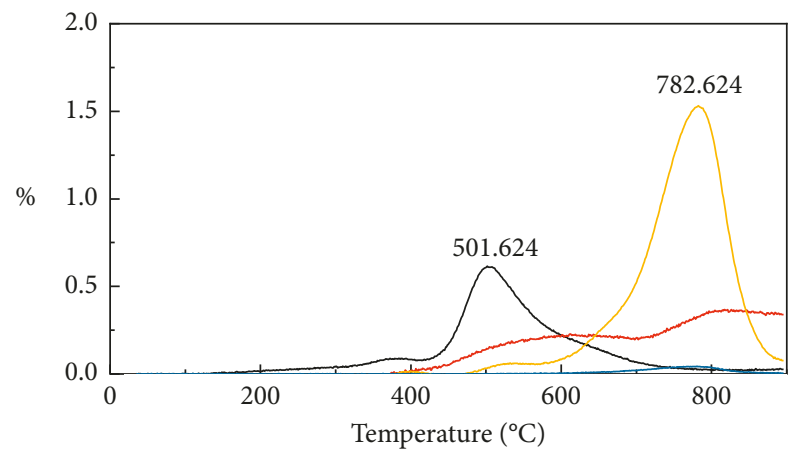

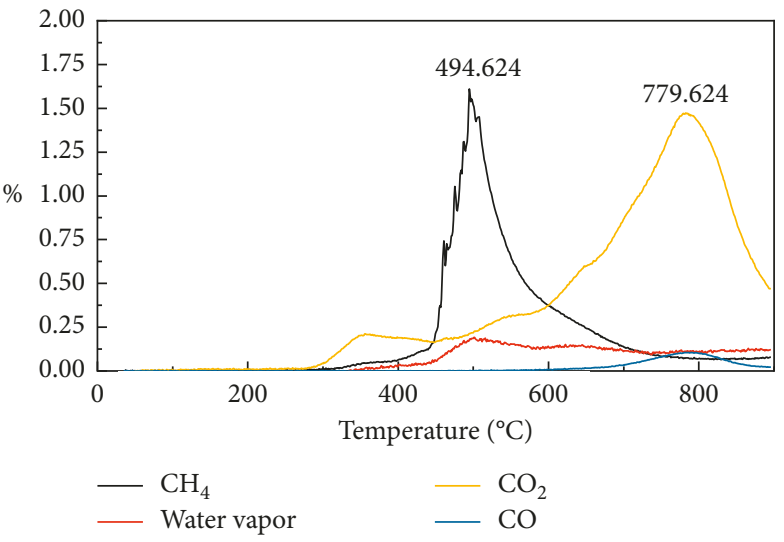

(b)
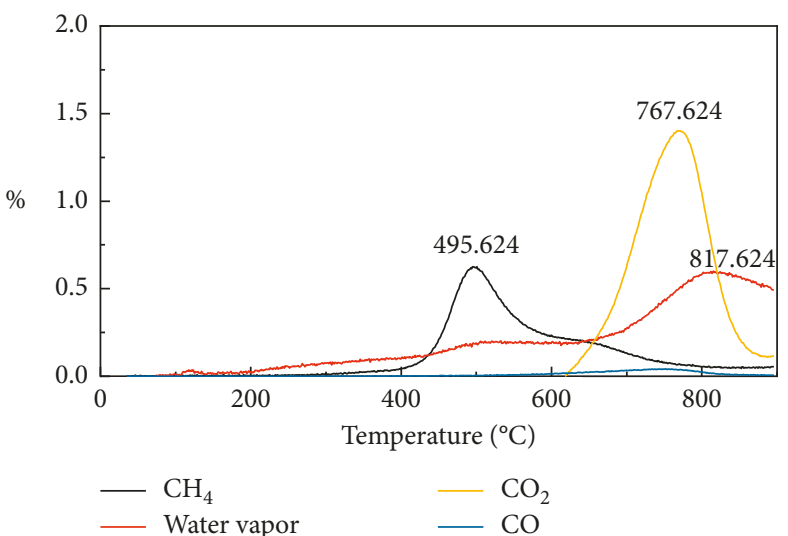

(d)

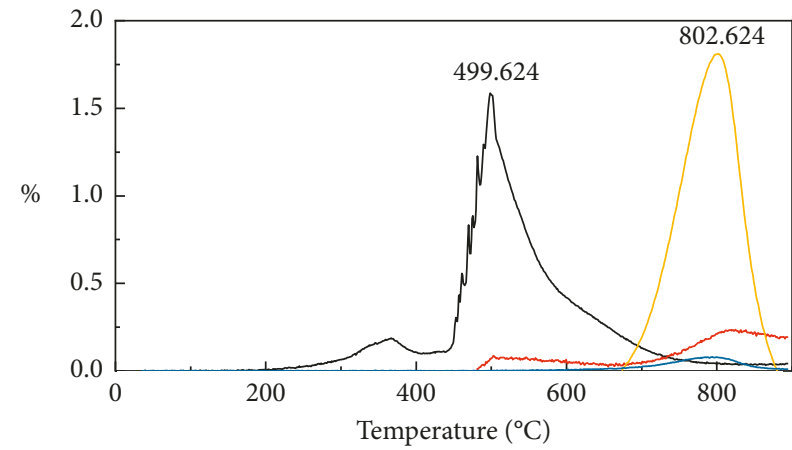

$\begin{array}{ll}-\mathrm{CH}_{4} & -\mathrm{CO}_{2} \\ - & \text { Water vapor }\end{array}$

(f)

(e)

Figure 3: Component diagrams of the different samples by permanent gas analysis. 

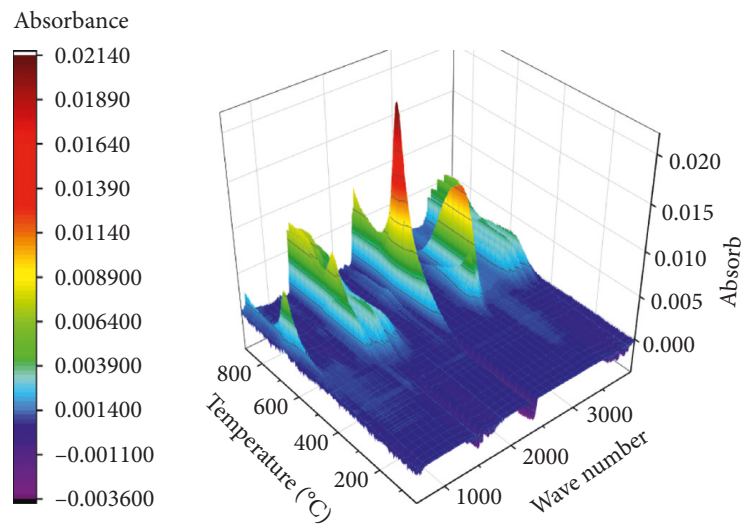

(a)
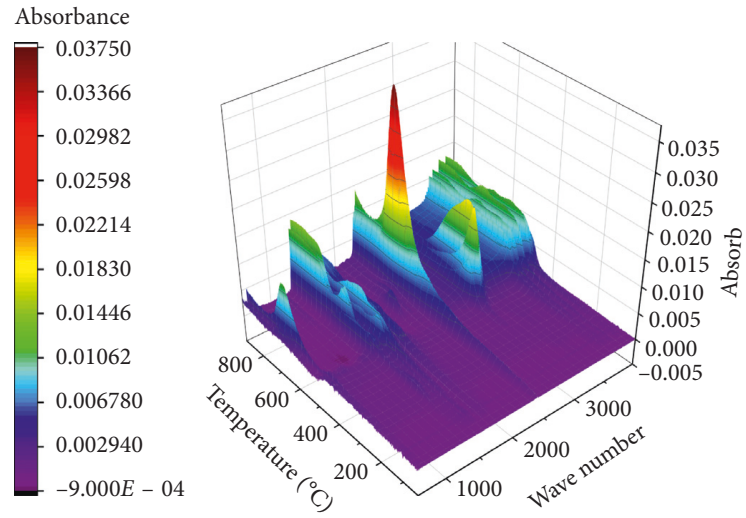

(c)

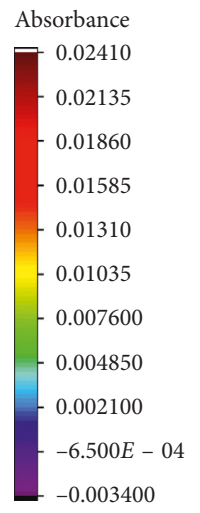

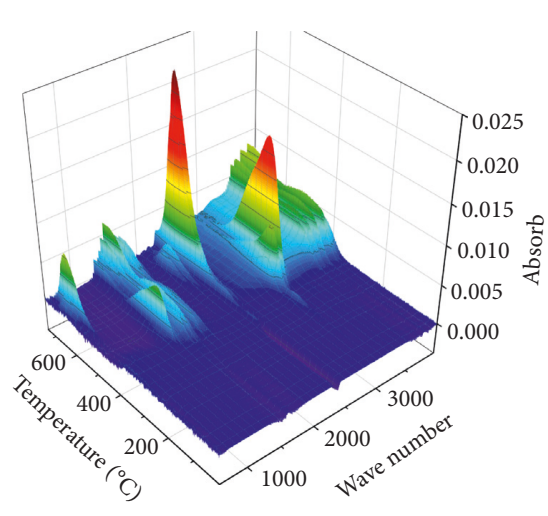

(e)
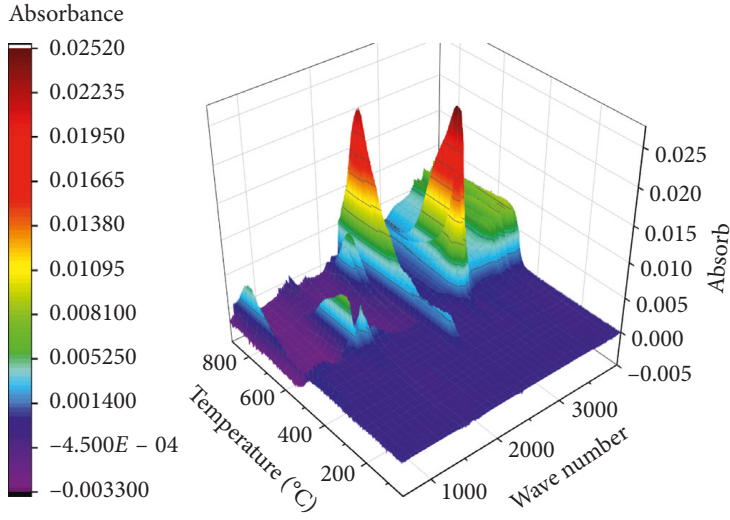

(b)
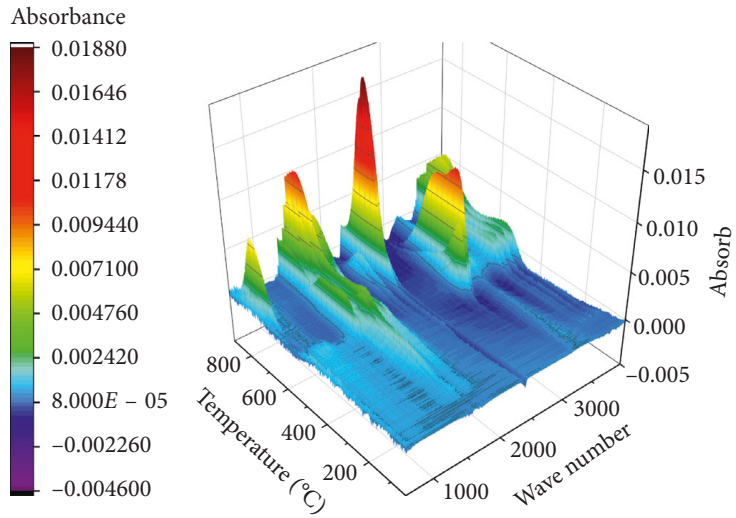

(d)

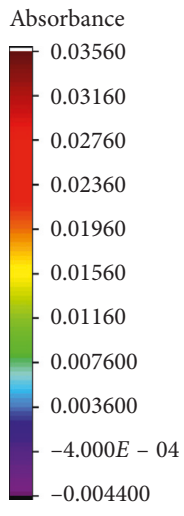

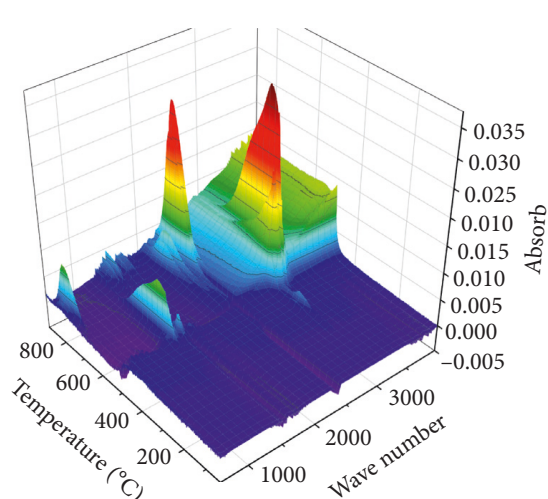

(f)

FIGURE 4: Time-domain analysis of FTIR spectroscopy results.

be divided into four stages with the increase of temperature: when the temperature is in the range of $35-400^{\circ} \mathrm{C}$, water separation and removal of adsorbed gases $\left(\mathrm{H}_{2} \mathrm{O}, \mathrm{N}_{2}\right)$ occur in coal. When the temperature is $400^{\circ} \mathrm{C}$, coal begins to undergo pyrolysis reaction, mainly to remove phenolic carboxyl functional groups with poor thermal stability. When the temperature continues to increase to $480^{\circ} \mathrm{C}$, coal is in the main pyrolysis stage. At this time, generation of volatile gases, tar, pyrolysis water, and other substances initiates, and the weight loss rate of coal reaches the peak. When the temperature is in the range of $530-900^{\circ} \mathrm{C}$, the pyrolysis reaction of coal is stable and the quality of pyrolysis products does not change.

3.2. Analysis of Permanent Gases. To understand the changes in the pyrolysis process, the gas released during the process was analyzed using a gas analyzer for the main components. The component diagrams of the different samples are shown in Figures 3(a)-3(f).

For all samples, methane $\left(\mathrm{CH}_{4}\right)$ gas was produced at the DTG peak temperature $\left(500^{\circ} \mathrm{C}\right)$. This indicates that the 


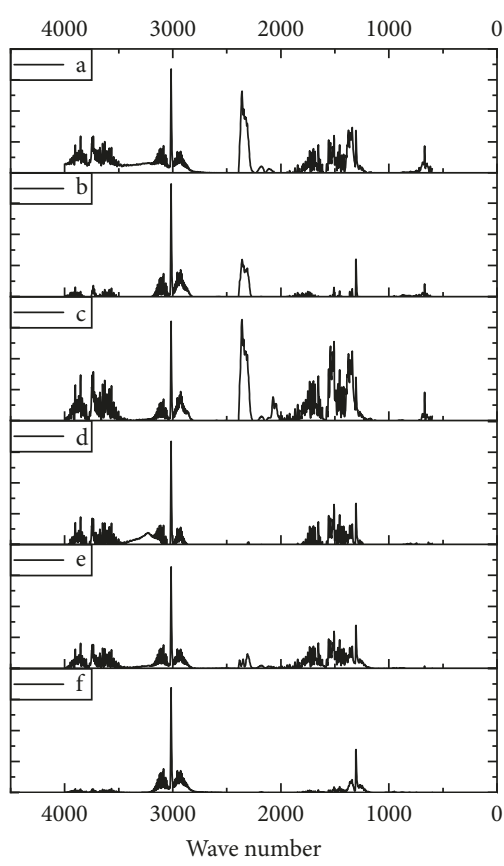

(a)

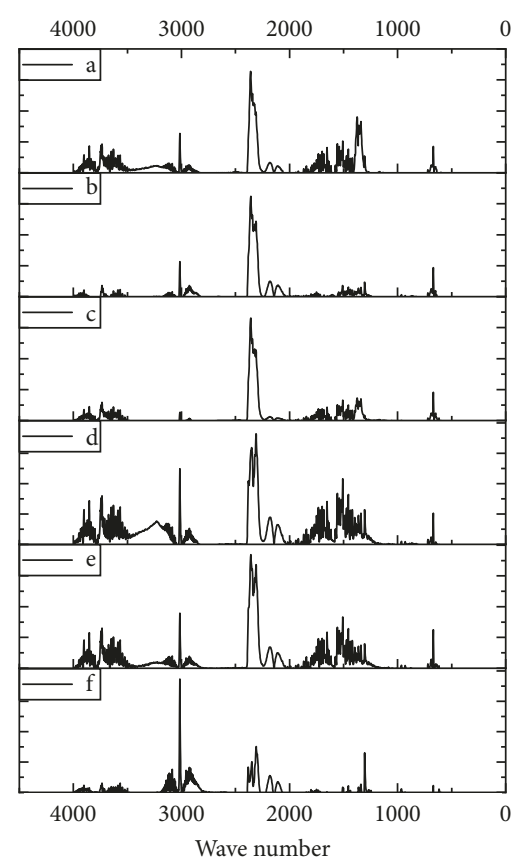

(b)

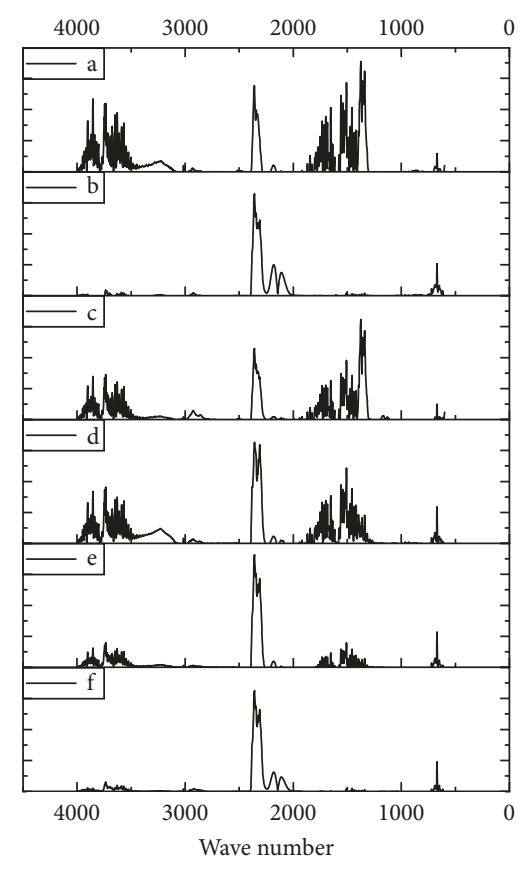

(c)

FIgURE 5: Comparison of the gas compositions of all coal samples at three temperatures.

organic volatiles begin to crack, and some of the easily detached substances are first separated. When the temperature is greater than $800^{\circ} \mathrm{C}\left(680^{\circ} \mathrm{C}\right.$ for samples a and c), the sample begins to carbonize and convert to coke. At this time, the structure of the coal is destroyed, and a large amount of $\mathrm{CO}_{2}$ is generated, leaving behind carbon tissue. Thereafter, due to the inert atmosphere, the coal does not continue to oxidize, leaving a portion of the fixed carbon structure.

For samples $\mathrm{c}$ and $\mathrm{d}$, water vapor generation starts at a lower temperature. For other samples, generation of water vapor begins simultaneously with $\mathrm{CH}_{4}$ production. This is similar to the coking process carried out at industrial level.

3.3. FTIR Spectroscopic Analysis. Although permanent gas analysis can provide information about the primary gases produced during the pyrolysis process, it is difficult to distinguish them for obtaining more details. Therefore, FTIR spectroscopy was employed to analyze the gas generated during the pyrolysis of coal under anaerobic conditions, and the corresponding results are shown in Figures 4(a)-4(f). For all samples, the main gases produced during the pyrolysis process were $\mathrm{CH}_{4}, \mathrm{CO}_{2}$, and water vapor. This result is consistent with the results of the gas analysis.

For samples a and $\mathrm{c}$, the $\mathrm{CO}_{2}$ content is much higher than that of other substances. For samples $b$, e, and $f$, the $\mathrm{CH}_{4}$ content is similar to the $\mathrm{CO}_{2}$ content. At the same time, for samples b, d, e, and $\mathrm{f}$, at temperatures above $800^{\circ} \mathrm{C}$, a double peak appears at a position of $2200 \mathrm{~cm}^{-1}$. This indicates the generation of a small amount of $\mathrm{CO}$ in these samples.

A comparison of the gas compositions of all coal samples at three temperatures $\left(600,700\right.$, and $\left.800^{\circ} \mathrm{C}\right)$ is shown in
Figure 5. Figure 5(a) demonstrates that at $600^{\circ} \mathrm{C}$, same peak appears at the position of wave number 3016, which indicates that all samples produce $\mathrm{CH}_{4}$ at this temperature. For samples a, b, and c, a peak appears at 2360, indicating the generation of $\mathrm{CO}_{2}$ at this temperature. This shows that it is easier for the three samples $\mathrm{a}, \mathrm{b}$, and $\mathrm{c}$ to remove the lighter short-chain structures.

Figure $5(\mathrm{~b})$ shows that at $700^{\circ} \mathrm{C}$, the peak area at 2360 gradually increases, which indicates that all coal samples begin to release $\mathrm{CO}_{2}$. At the same time, due to the nearreaction of the unstable short link, the release of $\mathrm{CH}_{4}$ begins to decrease. Noteworthy, the double peak appearing next to 3160 represents the production of CO. The pyrolysis conducted under oxygen at this temperature is not complete. At the same time, the messy peak around 1357 represents the generation of water vapor.

Figure 5(c) exhibits that at $800^{\circ} \mathrm{C}$, all the peaks at 3160 disappear, indicating that no more unreacted short chains are released at this temperature. At the same time, the release tendency of $\mathrm{CO}$ slows down, and the pyrolysis reaction begins to tend to remove excess hydrogen and oxygen bound in the carbon structure and releases it as water vapor.

For the three main components of the released gas, the corresponding IR wave numbers of $\mathrm{CH}_{4}, \mathrm{CO}_{2}$, and $\mathrm{H}_{2} \mathrm{O}$ are 3016,2360 , and 1357, respectively. The IR absorption ratetemperature diagram for these three wave numbers is shown in Figure 6. For the wave number 3016, the temperatures at which the six samples started to react were unexpectedly consistent, at around $420^{\circ} \mathrm{C}$. Moreover, the reaction tends to complete when the temperature is close to $800^{\circ} \mathrm{C}$. At a wavenumber of 2360 , most of the samples begin to dissociate at about $750^{\circ} \mathrm{C}$ and release $\mathrm{CO}_{2}$. Only sample $\mathrm{C}$ begins to react earlier and more intensely. This is attributed to the fact 


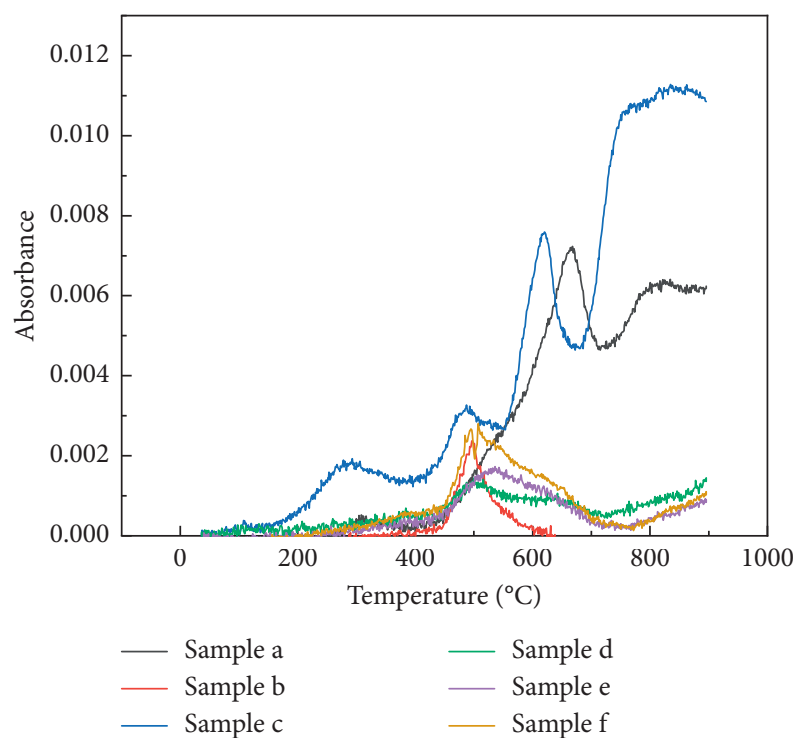

(a)

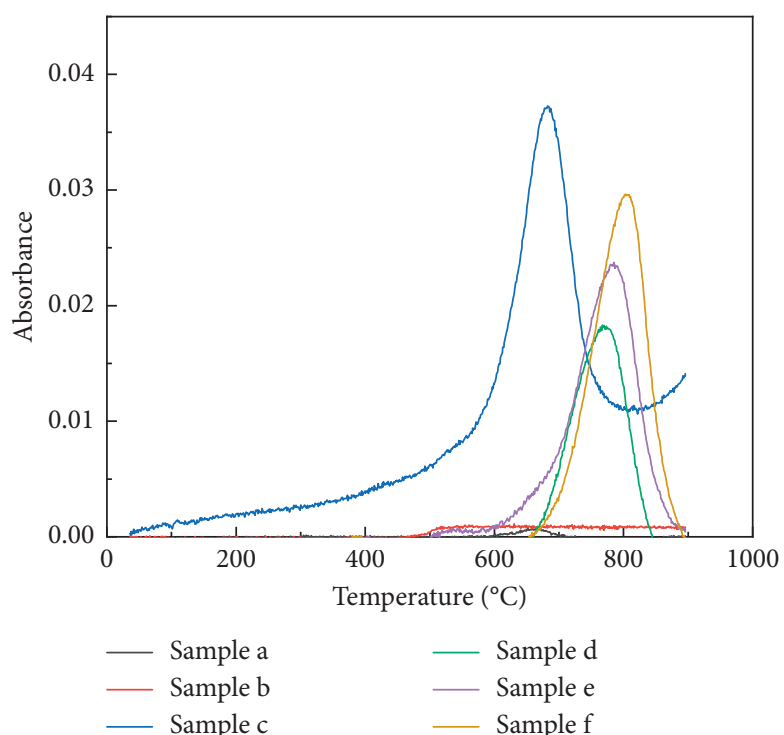

(b)

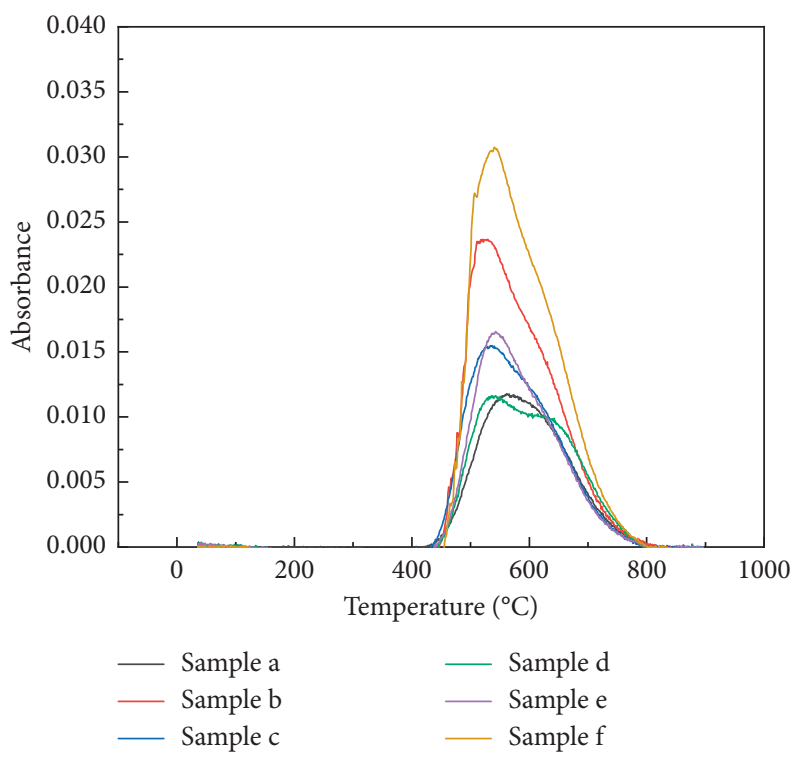

(c)

FIGURE 6: The infrared absorption rate-temperature diagram for three wave numbers.

that sample $\mathrm{C}$ has the lowest fixed carbon content among all samples, which provides a large amount of volatile matter, and the shorter carbon chain is easily dissociated. This conclusion also applies when the wave number is 1357. Compared to other samples, samples a and c release more water vapor.

\section{Conclusion}

In this study, thermogravimetric analysis (TGA) coupled with Fourier transform infrared (FTIR) spectroscopy was used to heat the coal samples of six different coalification degrees from room temperature to $1000^{\circ} \mathrm{C}$ at $20^{\circ} \mathrm{C} \cdot \mathrm{min}^{-1}$ under nitrogen atmosphere. The influence of coal degree and pyrolysis temperature on the content of pyrolysis products of coal was analyzed by the TG/DTG curve. FTIR spectroscopy was used to obtain the IR spectra of generated gases. The following results were obtained:

(1) The TG and DTG curve analysis indicates that the weight loss phenomenon starts at $400^{\circ} \mathrm{C}$, mainly to remove phenolic carboxyl functional groups with poor thermal stability. When the temperature continues to increase to $480^{\circ} \mathrm{C}$, coal is in the main pyrolysis stage, and volatile gases, tar, pyrolysis water, and other substances begin to produce. At this time, the weight loss rate of coal reaches the peak value. When the temperature reaches $800^{\circ} \mathrm{C}$, the pyrolysis reaction is basically completed and the reaction curve drops slowly. The maximum mass loss (MML) occurs in the range of 480 to $500^{\circ} \mathrm{C}$. The maximum 
weight loss rate is $32.72 \%$ and the minimum weight loss rate is $18.89 \%$. The mass loss during the pyrolysis process corresponds well with volatile matter contained in the sample.

(2) According to the permanent gas analysis, the gases produced are mainly $\mathrm{CH}_{4}, \mathrm{CO}_{2}, \mathrm{CO}$, and water vapor. When the temperature reaches $500^{\circ} \mathrm{C}, \mathrm{CH}_{4}$ begins to be produced, the organic matter in the coal begins to crack simultaneously, and separation of some volatile substances initiates. For most of the samples, the $\mathrm{CO}_{2}$ yield gets maximized at $800^{\circ} \mathrm{C}$, and the structure of the coal is destroyed leaving behind carbon tissue. Thereafter, the coal does not continue to oxidize due to the presence of the inert gas, leaving a portion of the fixed carbon structure.

(3) The results of IR spectroscopy reveal that the main gas components evolved at different temperatures. At $600^{\circ} \mathrm{C}$, the same peak appears at wave number 3016, indicating that all samples produce $\mathrm{CH}_{4}$. At $700^{\circ} \mathrm{C}$, the peak area at wave number 2360 increases, indicating that all coal samples begin to release $\mathrm{CO}_{2}$. The double peak at wave number 3160 represents the generation of $\mathrm{CO}$. At the same time, the release of $\mathrm{CH}_{4}$ begins to decrease due to the short-chain unstable near-reaction. At $800^{\circ} \mathrm{C}$, all peaks at wave number 3160 disappear, indicating that no unreacted short chain is released at this temperature. At the same time, the pyrolysis reaction begins to tend to remove excess hydrogen-oxygen conjugates from the carbon structure and is released as water vapor. Therefore, by detecting the content of $\mathrm{CH}_{4}$ and $\mathrm{CO}$ in the air, judging the internal temperature of the coal pile in time, and taking effective cooling measures, this study provides important guiding significance for reducing air pollution and casualties.

\section{Data Availability}

The experimental data used to support the findings of this study are included within the article.

\section{Conflicts of Interest}

The authors declare that they have no conflicts of interest.

\section{Acknowledgments}

The authors acknowledge the financial support by the Fundamental Research Funds for the Central Universities (no. 2018QNA12).

\section{References}

[1] C. L. Carlson and D. C. Adriano, "Environmental impacts of coal combustion residues," Journal of Environment Quality, vol. 22, no. 2, pp. 227-247, 1993.

[2] L. B. Clarke, "The fate of trace elements during coal combustion and gasification: an overview," Fuel, vol. 72, no. 6, pp. 731-736, 1993.
[3] D. Quispe, R. Pérez-López, L. F. O. Silva, and J. M. Nieto, "Changes in mobility of hazardous elements during coal combustion in Santa Catarina power plant (Brazil)," Fuel, vol. 94, pp. 495-503, 2012.

[4] J. Deng, Y. Xiao, Q. Li, J. Lu, and H. Wen, "Experimental studies of spontaneous combustion and anaerobic cooling of coal," Fuel, vol. 157, pp. 261-269, 2015.

[5] A. H. Clemens and T. W. Matheson, "The role of moisture in the self-heating of low-rank coals," Fuel, vol. 75, no. 7, pp. 891-895, 1996.

[6] J. N. Carras and B. C. Young, "Self-heating of coal and related materials: models, application and test methods," Progress in Energy and Combustion Science, vol. 20, no. 1, pp. 1-15, 1994.

[7] N. A. Öztaş and Y. Yürüm, "Pyrolysis of Turkish Zonguldak bituminous coal. Part 1. Effect of mineral matter," Fuel, vol. 79, no. 10, pp. 1221-1227, 2000.

[8] K. Sugawara, Y. Tozuka, T. Sugawara, and Y. Nishiyama, "Effect of heating rate and temperature on pyrolysis desulfurization of a bituminous coal," Fuel Processing Technology, vol. 37, no. 1, pp. 73-85, 1994.

[9] S. Krerkkaiwan, C. Fushimi, A. Tsutsumi, and P. Kuchonthara, "Synergetic effect during co-pyrolysis/gasification of biomass and sub-bituminous coal," Fuel Processing Technology, vol. 115, pp. 11-18, 2013.

[10] M. V. Kök, "An investigation into the combustion curves of lignites," Journal of Thermal Analysis and Calorimetry, vol. 64, no. 3, pp. 1319-1323, 2001.

[11] K. E. Ozbas, C. Hicyilmaz, M. V. Kök, and S. Bilgen, "Effect of cleaning process on combustion characteristics of lignite," Fuel Processing Technology, vol. 64, no. 1-3, pp. 211-220, 2000.

[12] M. Versan Kök, E. Özbas, C. Hicyilmaz, and Ö. Karacan, "Effect of particle size on the thermal and combustion properties of coal," Thermochimica Acta, vol. 302, no. 1-2, pp. 125-130, 1997.

[13] N. E. Altun, M. V. Kok, and C. Hicyilmaz, "Effect of particle size and heating rate on the combustion of silopi asphaltite," Energy \& Fuels, vol. 16, no. 3, pp. 785-790, 2002.

[14] M. V. Kök and M. R. Pamir, "ASTM kinetics of oil shales," Journal of Thermal Analysis and Calorimetry, vol. 53, no. 2, pp. 567-575, 1998.

[15] M. V. Kök, "Thermal analysis applications in fossil fuel science. Literature survey," Journal of Thermal Analysis and Calorimetry, vol. 68, no. 3, pp. 1061-1077, 2002.

[16] Y. Zhang, Y. Liu, X. Shi, C. Yang, W. Wang, and Y. Li, "Risk evaluation of coal spontaneous combustion on the basis of auto-ignition temperature," Fuel, vol. 233, pp. 68-76, 2018.

[17] Y. Xiao, Q.-W. Li, J. Deng, C.-M. Shu, and W. Wang, "Experimental study on the corresponding relationship between the index gases and critical temperature for coal spontaneous combustion," Journal of Thermal Analysis and Calorimetry, vol. 127, no. 1, pp. 1009-1017, 2017.

[18] X. Qi, D. Wang, H. Xin, and G. Qi, "In situ FTIR study of realtime changes of active groups during oxygen-free reaction of coal," Energy \& Fuels, vol. 27, no. 6, pp. 3130-3136, 2013.

[19] S. Materazzi, "Thermogravimetry-infrared spectroscopy (TG-FTIR) coupled analysis," Applied Spectroscopy Reviews, vol. 32, no. 4, pp. 385-404, 1997.

[20] K. Slopiecka, P. Bartocci, and F. Fantozzi, "Thermogravimetric analysis and kinetic study of poplar wood pyrolysis," Applied Energy, vol. 97, pp. 491-497, 2012.

[21] M. X. Fang, D. K. Shen, Y. X. Li, C. J. Yu, Z. Y. Luo, and K. F. Cen, "Kinetic study on pyrolysis and combustion of wood under different oxygen concentrations by using TG- 
FTIR analysis," Journal of Analytical and Applied Pyrolysis, vol. 77, no. 1, pp. 22-27, 2006.

[22] H. M. Zhu, J. H. Yan, X. G. Jiang, Y. E. Lai, and K. F. Cen, "Study on pyrolysis of typical medical waste materials by using TG-FTIR analysis," Journal of Hazardous Materials, vol. 153, no. 1-2, pp. 670-676, 2008.

[23] N. Gao, A. Li, C. Quan, L. Du, and Y. Duan, "TG-FTIR and Py-GC/MS analysis on pyrolysis and combustion of pine sawdust," Journal of Analytical and Applied Pyrolysis, vol. 100, pp. 26-32, 2013.

[24] Q. Liu, S. Wang, Y. Zheng, Z. Luo, and K. Cen, "Mechanism study of wood lignin pyrolysis by using TG-FTIR analysis," Journal of Analytical and Applied Pyrolysis, vol. 82, no. 1, pp. 170-177, 2008.

[25] K. Wang, J. Deng, Y.-n. Zhang, and C.-p. Wang, "Kinetics and mechanisms of coal oxidation mass gain phenomenon by TGFTIR and in situ IR analysis," Journal of Thermal Analysis and Calorimetry, vol. 132, no. 1, pp. 591-598, 2018.

[26] Y. Zhang, Y. Li, Y. Huang, S. Li, and W. Wang, "Characteristics of mass, heat and gaseous products during coal spontaneous combustion using TG/DSC-FTIR technology," Journal of Thermal Analysis and Calorimetry, vol. 131, no. 3, pp. 2963-2974, 2017.

[27] X. Qi, Q. Li, H. Zhang, and H. Xin, "Thermodynamic characteristics of coal reaction under low oxygen concentration conditions," Journal of the Energy Institute, vol. 90, no. 4, pp. 544-555, 2017.

[28] X. Guo, C. Deng, X. Zhang, and Y. Wang, "Formation law of hydrocarbon index gases during coal spontaneous combustion in an oxygen-poor environment," Energy Sources, Part A: Recovery, Utilization, and Environmental Effects, vol. 41, no. 5, pp. 626-635, 2019. 

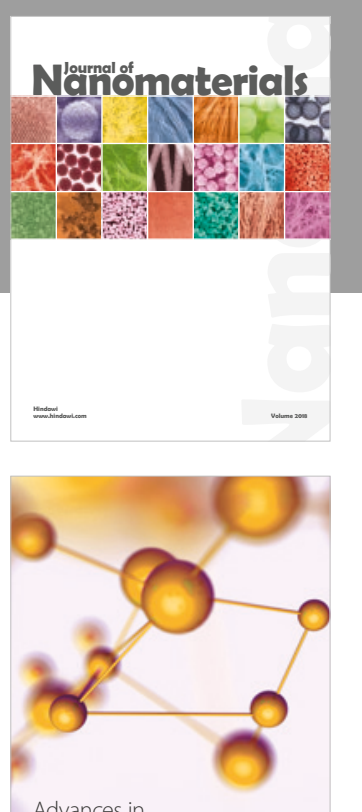

Physical Chemistry
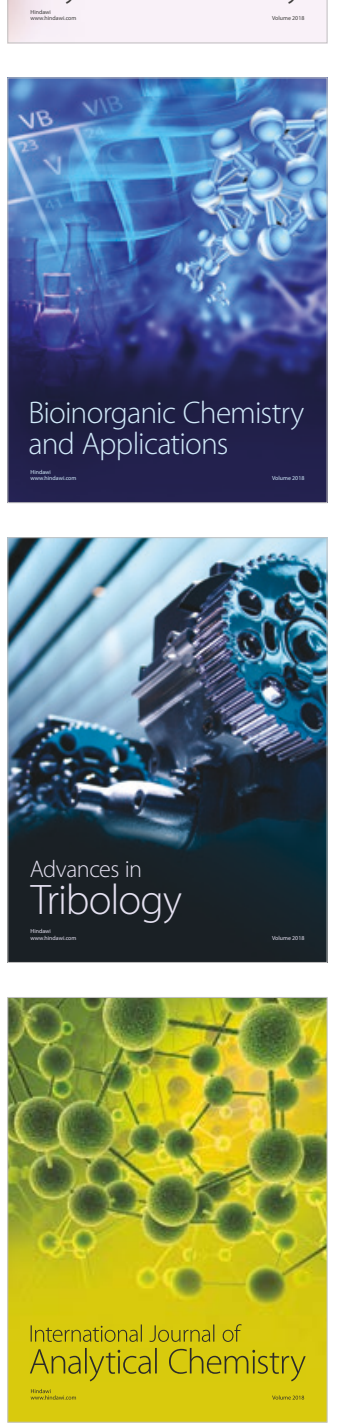

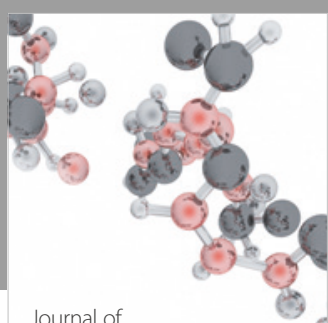

Analytical Methods

in Chemistry

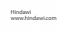

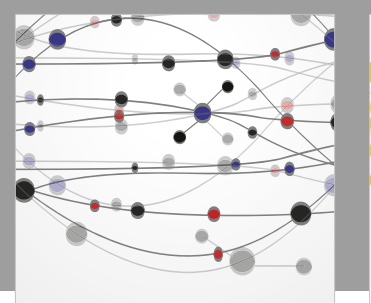

The Scientific World Journal

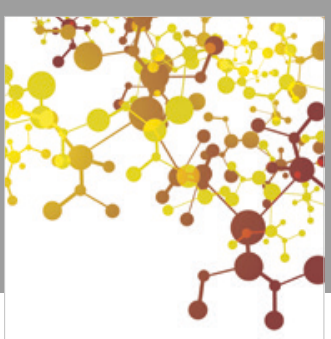

Journal of

Applied Chemistry
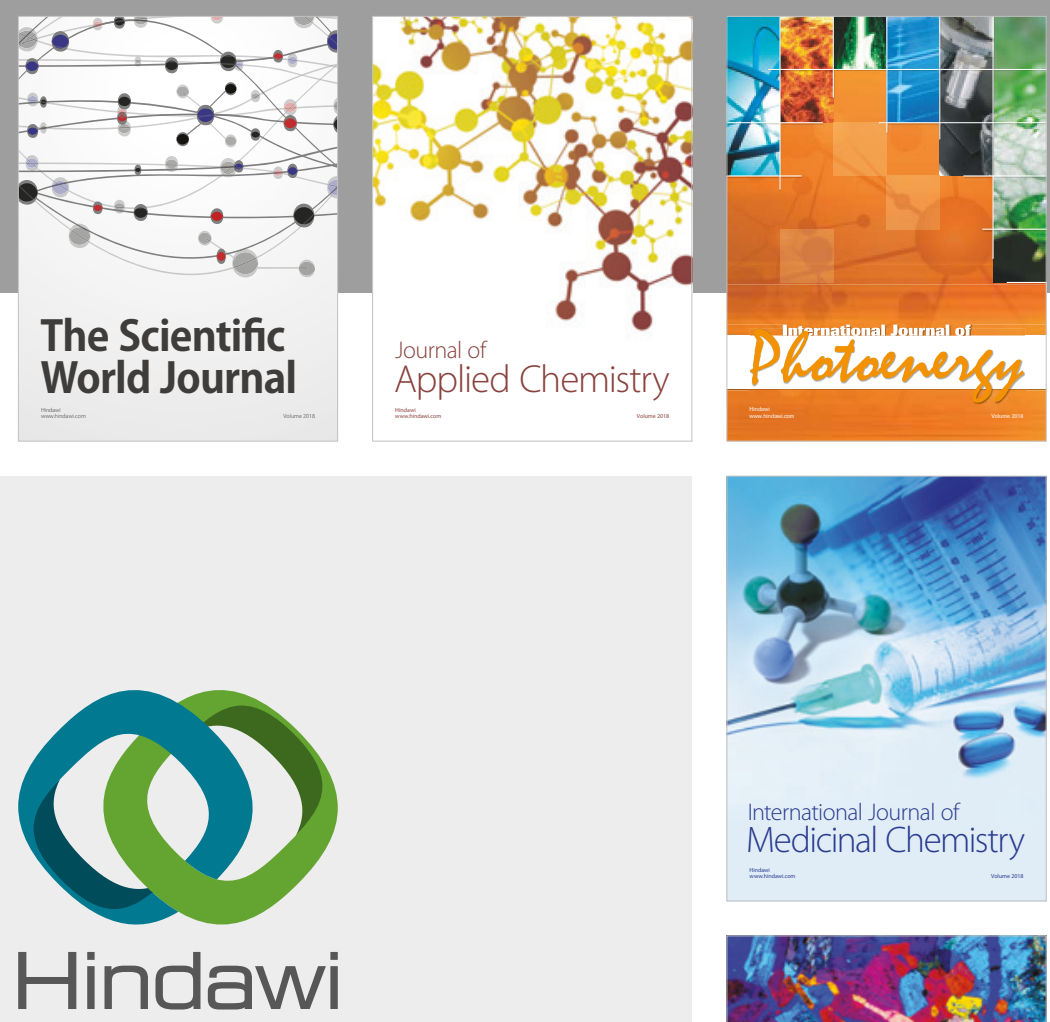

Submit your manuscripts at

www.hindawi.com
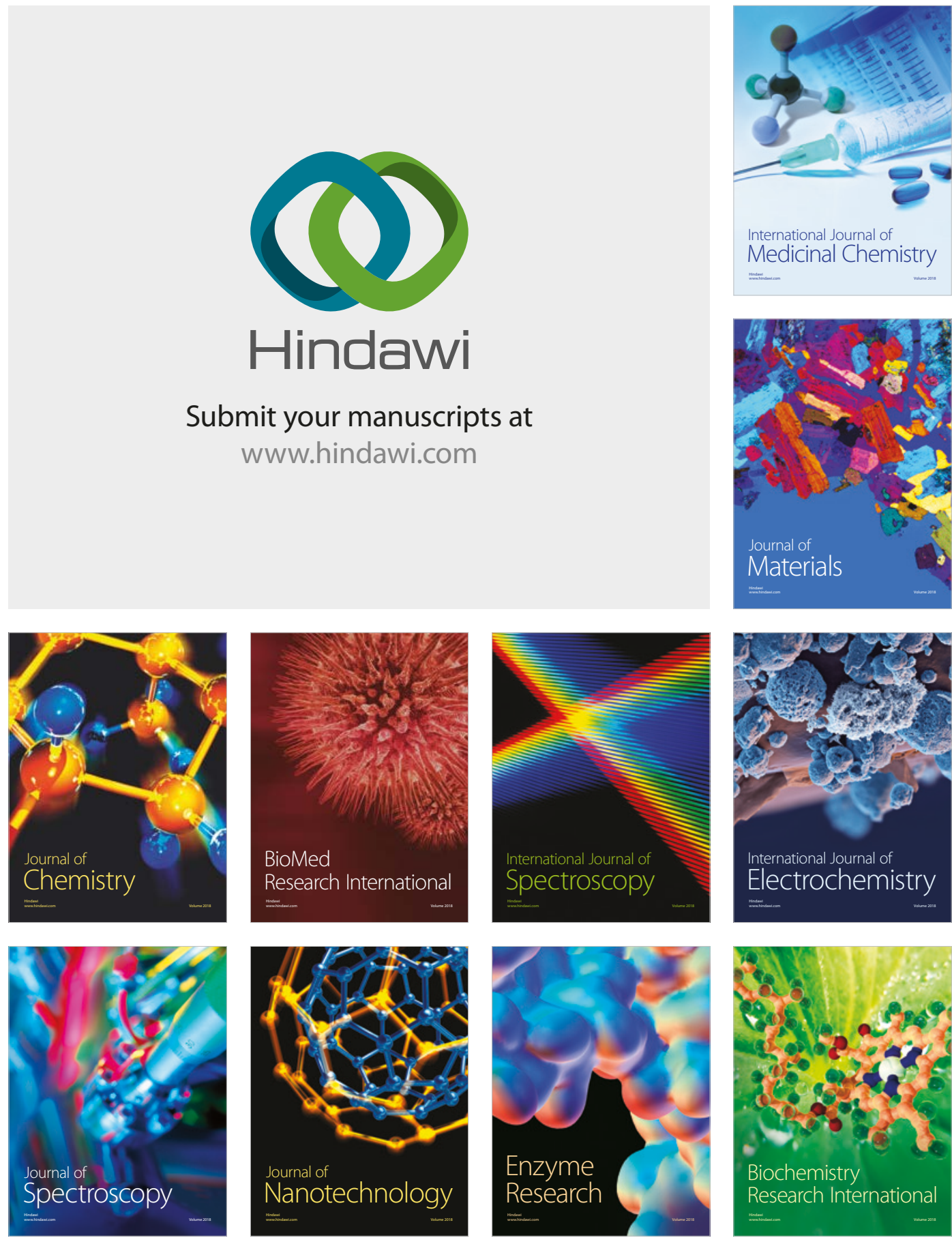
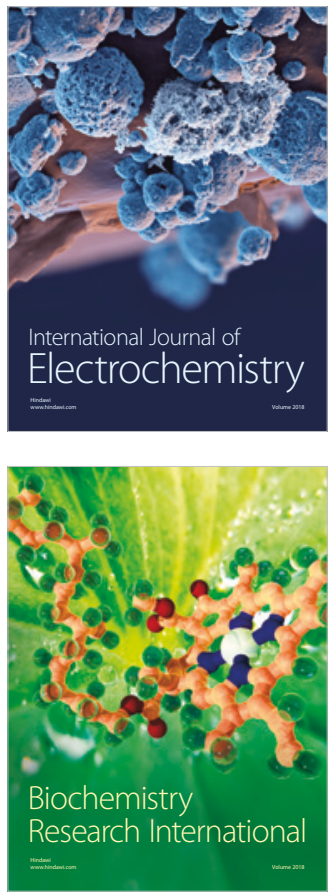